REVIEW

\title{
Diabetes in African Americans
}

\author{
M C Marshall Jr
}

Postgrad Med J 2005;81:734-740. doi: 10.1136/pgmj.2004.028274

African Americans have a high risk for type 2 diabetes. Genetic traits, the prevalence of obesity, and insulin resistance all contribute to the risk of diabetes in the African American community. African Americans have a high rate of diabetic complications, because of poor glycaemic control and racial disparities in health care in the USA. African Americans with diabetes may have an atypical presentation that simulates type 1 diabetes, but then their subsequent clinical course is typical of type 2 diabetes. Culturally sensitive strategies, structured disease management protocols, and the assistance of nurses, diabetic educators, and other health care professionals are effective in improving the outcome of diabetes in the African American community.

Correspondence to: Dr M C Marshall, The Endocrine Institute, 21 Seymour Place, White Plains, New York 10605, USA; mmarshall@ endocrineinstitute.com

Submitted 31 August 2004 Accepted 10 March 2005
T he estimated prevalence of diabetes in the USA is nearly 16 million people. ${ }^{1}$ Ninety per cent of all people with diabetes in the USA have type 2 diabetes, and that percentage is even higher for patients over the age of 45 years. ${ }^{2}$ African Americans constitute an ethnic population that has been characterised by the American Diabetes Association as having a high risk for diabetes. ${ }^{3}$ The prevalence of diagnosed diabetes is 1.6-fold higher in African Americans compared with white Americans. ${ }^{1}$ While the incidence of type 1 diabetes is fourfold higher in white Americans compared with African Americans, the prevalence of type 2 diabetes is 1.4 -fold to 2.3-fold higher in African Americans. ${ }^{4}$ The increased prevalence of type 2 diabetes among African Americans extends to children, adolescents $^{5}$ and even to US military personnel on active duty. ${ }^{6}$ In addition, African Americans bear a disproportionate burden of the morbidity and mortality associated with diabetes. Consequently, diabetic African Americans have a higher rate of retinopathy, microalbuminuria, end stage renal disease, lower extremity amputation, and mortality compared with white Americans. ${ }^{7-14}$

\section{RISK FACTORS}

The reasons for these findings are multifaceted..$^{15}{ }^{16}$ The most popular hypotheses that have been proposed are specific genetic factors and environmental factors. One genetic theory is that the prevalence of G6PD deficiency in African Americans in combination with a Western diet is a risk factor for type 2 diabetes. ${ }^{17}$ A more widely held theory is the thrifty gene theory. This theory repeated periods of famine derived a survival suggests that populations that were subject to advantage from a "thrifty" gene; that is, a genetic predilection for efficient storage of fat. Such fat storage would sustain the person until food became available again. If such a population now resides in a land of plenty, for example, the West African diaspora to America, then the same genetic trait for efficient fat storage would lead to obesity and consequent insulin resistance. ${ }^{18} 19$ However, native Africans are a heterogeneous group, and African Americans, after centuries of genetic admixture, are even more heterogeneous. For these, and other reasons, the thrifty gene hypothesis has been disputed..$^{20}$

Obesity is associated with insulin resistance and type 2 diabetes. Obesity is more prevalent among African Americans than white Americans. ${ }^{422} 23$ This is especially true for women; it is estimated that diabetes can be attributed to abdominal obesity in $39.9 \%$ of African American women, compared with $24.0 \%$ of white American women. ${ }^{4}$ Nevertheless, the increased prevalence of diabetes in African Americans cannot be accounted for solely by differences in weight. ${ }^{44-26}$

Physical inactivity is a risk factor for type 2 diabetes, ${ }^{27}{ }^{28}$ and physical activity is clearly beneficial for type 2 diabetes. ${ }^{29}$ Physical activity is decreased in African American women and adolescent girls. ${ }^{3031}$ This also contributes to their risk for diabetes.

Insulin resistance is a precursor to glucose intolerance and overt diabetes. The issue of insulin resistance among African Americans is quite problematic. African American children, especially girls, have a higher rate of insulin resistance than white children. ${ }^{32}{ }^{33}$ However, among adults, some investigators have found similar rates of insulin resistance between African Americans and white Americans with type 2 diabetes. ${ }^{34}$ Other investigators have found a dichotomous population of diabetic African Americans, with half their patients exhibiting insulin resistance and half exhibiting insulin sensitivity. ${ }^{35}$ When non-diabetic African American subjects are studied, increased insulin resistance has been found in African American men and women, even after adjusting for body weight and fat distribution, in some studies, ${ }^{25} 36$ but only in non-obese African American women, compared with non-obese white women, in another study. ${ }^{37}$ The variability of results in these studies may be attributable to different methods of assessing insulin resistance.

Abbreviations: SES, socioeconomic status; DCCT, diabetes control and complications trial; UKPDS, United Kingdom prospective diabetes study; DPP, diabetes prevention program; DKA, diabetic ketoacidosis; MODY, maturity onset diabetes of the young 


\section{MORBIDITY}

While there are multiple reasons for the increased prevalence of diabetes among African Americans, a prominent reason for the increased rate of complications among African American diabetic patients is the lack of adequate control. The diabetes control and complications trial (DCCT) ${ }^{38}$ and the United Kingdom prospective diabetes study (UKPDS) ${ }^{39}$ have clearly shown, in type 1 and type 2 diabetes, respectively, that improved glycaemic control is associated with a lower risk of microvascular complications. Although the number of African Americans in the DCCT and the number of African Carribeans in the UKPDS was less than $10 \%$ of each study population, it is reasonable to assume that the findings of these studies are equally applicable to ethnic minorities.

Adult diabetic patients in the USA, of all races, are generally poorly controlled..$^{40}$ However, racial differences in glycaemic control have been amply reported; African American diabetic patients are less well controlled than white diabetic patients. ${ }^{10}{ }^{42-46}$ African American diabetic patients are less likely to have their treatment intensified to improve glycaemic control. ${ }^{46} 47$ One possible explanation for this phenomenon is that African Americans, as a group, have a lower socioeconomic status (SES) than white Americans. Indigent patients have less access to health care and often present with diseases that are already far advanced. However, even when adjusting for SES, access to health care and severity of disease, racial differences in glycaemic control persist. $^{42} 43$

Another important factor in the increased morbidity in African Americans with diabetes is racial disparities in health care. The Institute of Medicine (IOM) published an extensive report on the topic of disparities in health care in the USA. ${ }^{48}$ The IOM found that all racial and ethnic minorities in the USA receive a lower quality of health care, regardless of SES, insurance coverage, age, or comorbid conditions. In a study of Medicare beneficiaries, African American diabetic patients were less likely to have glycosylated haemoglobin measurements, lipid testing, or ophthalmological visits than white diabetic patients. ${ }^{8}$ All the subjects in this study were age 65 years or older and were enrolled in Medicare, a US government funded health insurance that is widely accepted by physicians in the USA. Thus, SES, age, and access to health care were not responsible for the discrepancy in quality of care. Similarly, a study of US military veterans with diabetes found a discrepancy in care. All the subjects received their primary care within the Veterans Affairs health care system; therefore, SES and access to care were not factors. Nevertheless, African American diabetic veterans were more likely to undergo a lower extremity amputation than white diabetic veterans. ${ }^{13}$ African American diabetic veterans are also more likely to have diabetic nephropathy and end stage renal disease than white diabetic veterans, after adjustment for age, sex, and economic status. ${ }^{14}$ A discussion of the myriad and complex causes and manifestations of racial and ethnic inequalities in the USA is beyond the scope of this review.

\section{TREATMENT}

The cornerstone of management of type 2 diabetes is lifestyle changes-that is, diet and exercise. ${ }^{34}$ Pharmacological intervention is always in addition to, not in place of lifestyle changes. The diabetes prevention program (DPP) showed that intensive lifestyle intervention is more effective than metformin in preventing the progression from impaired glucose tolerance to overt diabetes. ${ }^{50}$ The DPP was a prevention trial, rather than a therapeutic trial for patients already diagnosed with diabetes. Nevertheless, the DPP has the value of having been designed to intentionally recruit half of its participants from racial or ethnic minority groups. ${ }^{51}$
Twenty per cent of the 3200 participants were African Americans. In a subgroup analysis of the DPP, there was no significant difference in treatment effects based on sex, race, or ethnic group. Studies of African Americans with type 2 diabetes have shown that improved levels of physical activities, effective medical nutrition treatment, and consequent improved glycaemic control can be achieved with culturally appropriate strategies. ${ }^{52}{ }^{53}$

When lifestyle changes are insufficient for adequate glycaemic control, pharmacological intervention is necessary. Discussing "evidence based" pharmacological recommendations for African American diabetic patients is a challenge because of the paucity of randomised controlled studies that specifically investigate African Americans. For example, despite the fact that biological responses to pharmaceuticals vary among different ethnic and racial groups, ${ }^{54}$ scarce data are available on the pharmacokinetics of oral antidiabetic drugs among African Americans. There are 10 oral antidiabetic drugs listed in the Physicians' Desk Reference (PDR): the sulfonylureas-glyburide (glibenclamide), glipizide, and glimepiride; the biguanide-metformin; the thiazolidinediones-pioglitazone and rosiglitazone; the meglitinidesrepaglinide and nateglinide; and the $\alpha$-glucosidase inhibitors-acarbose and miglitol..$^{55}$ The product information in the PDR for eight of the 10 agents has no information on the effects of race upon the pharmacokinetics of the drug. The product information of two agents state that race has no influence upon the pharmacokinetics of the drug. The product information for six of 10 agents has no information on the effects of race upon drug efficacy. Four agents have product information stating that the efficacy of the drug is unaffected by race. African Americans constitute from $9.3 \%$ to $21.5 \%$ of the patient population in the studies cited in these agents' product information..$^{55}$

There are several excellent, recently published reviews of the pharmacological treatment of type 2 diabetes. ${ }^{56-58}$ These reviews detail the dose range, mode of action, adverse effects, and recommended use for the available pharmacological agents. The different classes of oral antidiabetic drugs have equivalent clinical efficacy, and most agents will lower HbAlc levels by $1 \%-2 \%$. Combination treatment is synergistic and more effective than monotherapy. The underlying rationale for the selection of specific oral agents is the known pathophysiology of type 2 diabetes. The initial defect in type 2 diabetes is insulin resistance, but it is followed by a progressive decline in $\beta$ cell function. The insulin resistance is manifested by accelerated hepatic glucose production and decreased muscle uptake of glucose. Impaired $\beta$ function is manifested by impaired insulin secretion, failure to respond to oral agents, and ultimately a need for insulin treatment. ${ }^{39}$ 56-58

Metformin is recommended as initial treatment for most type 2 diabetic patients, especially overweight patients. ${ }^{39} 56$ The fear of lactic acidosis with metformin treatment is no longer warranted. ${ }^{59}$ Sulfonylureas are often preferred for lean type 2 diabetic patients who seem to be more insulin deficient than insulin resistant. ${ }^{60}$ Thiazolidinediones have been used successfully as monotherapy for the insulin resistant patient or in combination therapy with sulfonylureas, metformin, and insulin..$^{58}{ }^{60}$ The $\alpha$-glucosidase inhibitors have prominent gastrointestinal side effects that limit their tolerance by patients. The $\alpha$-glucosidase inhibitors and the meglitinides are used primarily to dampen postprandial glycaemic excursions.

An evolving concept is the use of combination therapy earlier in the management of type 2 diabetes. The array of available oral agents with different mechanisms of action results in several synergistic combinations, and combination 
therapy may permit lower doses of each individual agent and hence fewer side effects. ${ }^{60}$

Of course, all of the above is predicated upon studies that primarily enrolled white subjects. A Medline search for randomised controlled trials of African American diabetic patients resulted in only four citations. ${ }^{61-64}$ Three of the four studies involved African Americans who did not have diabetes, but were at increased risk for diabetes by dent of glucose intolerance, a family history of diabetes, or a history of gestational diabetes. ${ }^{61}{ }^{6264}$ Two of these three papers studied glipizide, and the third studied troglitazone, which is no longer available. The fourth paper involved insulin treated African Americans with type 2 diabetes, and studied the effects of pramlintide. ${ }^{63}$ Pramlintide is an amylin analogue that suppresses glucagon secretion, but it is not commercially available. In the absence of specific evidence, the recommendations for the use of oral antidiabetic drugs in African Americans with type 2 diabetes are, by default, the same as the recommendations for the general population. ${ }^{39}$ 56-58 60

Insulin therapy, either alone or in combination with oral agents, improves glycaemic control in type 2 diabetes. ${ }^{65-68}$ This may be particularly true for African Americans with type 2 diabetes. ${ }^{65}$ Certainly, patients who fail to respond to oral agents will need insulin therapy, and lean patients with type 2 diabetes are more likely to require insulin therapy early in the course of their disease. ${ }^{69}$ When NPH insulin is prescribed as a night time dose, it is best taken at bedtime rather than dinner time. ${ }^{70}$ Combinations of insulin with oral agents often permit lower doses of insulin, ${ }^{67}$ but such combinations are not always more effective than insulin alone. ${ }^{69}$ The major side effects of insulin therapy are weight gain and hypoglycaemia. These side effects are also the major barriers to the start of insulin therapy by physicians and important barriers to the acceptance of insulin therapy by patients. Insulin glargine, the once daily "basal" insulin, has been compared with NPH insulin and found to effect improved glycaemic control with a significantly lower incidence of weight gain and hypoglycaemia, especially nocturnal hypoglycaemia. ${ }^{68}$ Insulin glargine has been successfully used in combination with oral agents in type 2 diabetes. It has also been efficacious in combination with pre-meal rapid acting insulins in both type 1 and type 2 diabetes.

Continuous subcutaneous insulin infusion (CSII) via insulin pumps has been, in the author's experience, equally effective in African American and white type 1 diabetic patients. Brittle diabetic patients (characterised by erratic swings in glucose levels) can benefit from a more narrow range of glycaemic excursions consequent to CSII. CSII is particularly useful for patients whose lifestyles preclude regimented schedules, such as shift workers. Although CSII is primarily used in type 1 diabetic patients, it is also effective in type 2 diabetic patients who require insulin therapy. CSII should be started and managed by endocrinologists who have experience with insulin pump therapy. However, primary care physicians should keep in mind the usual indications for considering CSII: brittle diabetes, pronounced Dawn phenomenon, pregnancy or pre-conception planning, shift work, and erratic lifestyle.

A critical issue in the management of African American diabetic patients is the lack of appropriate intensification of treatment, both lifestyle changes and pharmacological therapy, to achieve adequate glycaemic control. Multiple reasons have been cited for this persistent problem. Patient related factors include poor compliance with self monitoring, poor adherence to treatment, economic factors such as costs of test strips and drugs, literacy rate, lack of diabetes education, and sociocultural factors. Physician related factors include physicians' perceptions and/or bias in treating African American patients, communication barriers, as well as time constraints in a busy clinical practice. These factors are often interconnected, particularly when there is nonconcordance of physician-patient ethnicity. For example, if a physician has a judgmental attitude toward an African American patient and a preconceived notion that the patient cannot or will not comply with a regimen, and consequently gives only perfunctory attention to that patient, such an attitude will be evident to the patient and fuel any distrust the patient may already have for the medical profession in general and for a physician of a different ethnicity in particular. In this circumstance, non-compliance with treatment becomes a self fulfilling prophecy. In addition, although studies have shown that African American diabetic patients are less compliant with pharmacological treatment than white diabetic patients, medication compliance in itself may simply be a surrogate for better or more intensive diabetes education for a given patient. Also, while studies have correlated non-compliance with poor glycaemic control, non-compliance alone does not account for the full extent of racial differences in glycaemic control. ${ }^{46}$

Fortunately, strategies have been developed to overcome some of the barriers that prevent adequate management of diabetes in African Americans. ${ }^{46} 5253$ 71-75 Such strategies have been proved effective in various venues, including a large prepaid health plan with enrollees who are employed, ${ }^{75}$ community clinics for indigent patients, ${ }^{73}$ hospital based diabetes clinics, ${ }^{71}{ }^{72} 74$ and a university based primary care clinic. ${ }^{46}$ One interesting strategy is the use of commercially available rapid HbAlc assays. Physicians who have access to current HbAlc data at the time that a patient is seen are more likely to appropriately intensify treatment than physicians who do not have contemporaneous access to HbAlc data. ${ }^{74}$ Most successful strategies have a prominent common theme: the utility of nurses, pharmacists, dietitians, and diabetes educators working with protocols and treatment algorithms, under the supervision of endocrinologists. ${ }^{71-73}$ Nurses and other allied health care professionals are often able to spend more time with patients, often have better communication skills, and may even be more compassionate than physicians. $^{72}$ They are also more likely to adhere to treatment algorithms and to intensive therapy appropriately. Studies have shown the benefits of time and effort spent on telephoning patients between visits, re-scheduling missed appointments, facilitating transportation to clinics, communicating with referring physicians, and facilitating appointments with ancillary services (for example, podiatry, ophthalmology). ${ }^{71-73}$ This is, of course, time consuming and labour intensive. However, the long term gain, in terms of improved glycaemic control and reduced morbidity and mortality, is well worth the short term expense.

\section{CHILDREN}

African American children and adolescents with diabetes can present special challenges. The clinician should recognise that not all diabetes presenting in childhood or adolescence is type 1 diabetes. There is a rising incidence of type 2 diabetes in this age group, because of a rising incidence of obesity. ${ }^{76}$ The differential diagnosis of childhood or adolescent diabetes includes classic type 1 diabetes, maturity onset diabetes of the young (MODY), typical type 2 diabetes, and the atypical diabetes seen in African Americans. ${ }^{77-80}$

Typical type 1 diabetes is associated with islet cell autoantibodies and often presents with diabetic ketoacidosis (DKA). Classic MODY occurs predominantly in white youth, under the age of 25 years. However, less that $5 \%$ of childhood diabetes among white diabetic children is attributable to MODY. MODY is inherited as an autosomal dominant trait. At least eight different genetic mutations have been described.$^{79}$ MODY is considered a form of type 2 diabetes 


\section{Key points}

- The prevalence of type 2 diabetes is higher in African Americans compared with white people, and African Americans bear a disproportionate burden of the morbidity and mortality associated with diabetes.

- Racial differences in glycaemic control have been reported. Racial and ethnic minorities in the USA receive lower quality health care.

- There is a paucity of randomised controlled studies that specifically investigate pharmacological treatment of African American diabetic patients.

- African Americans with atypical diabetes can present with diabetic ketoacidosis, but have a subsequent clinical course typical of type 2 diabetes.

- Intensive treatment of African Americans with newly diagnosed diabetes can lead to remission of diabetes in $30 \%-40 \%$ of patients.

- The use of case management nurses and structured disease management protocols can significantly improve glycaemic control and diabetes outcomes among African American diabetic patients.

in that it is non-ketotic and generally non-insulin requiring. Typical type 2 diabetes in children and teenagers of all races is associated with abdominal obesity, decreased physical activity, and insulin resistance. ${ }^{76}$ Atypical diabetes may constitute $10 \%$ of African American diabetic youth and is quite similar to the atypical diabetes in African American adults (vida infra). Unlike classic type 1 diabetes or MODY, $50 \%$ of African American youth with atypical diabetes are obese. Also unlike type 1 diabetes, these patients lack islet cell autoantibodies and have a subsequent clinical course that is similar to type 2 diabetes. However, unlike typical type 2 diabetes, atypical diabetes generally presents acutely, often with weight loss and ketosis.

The management of children and teenagers with diabetes can be difficult. Nevertheless, tight control is warranted to prevent microvascular, and possibly macrovascular complications. ${ }^{76}{ }^{81}$ As for adult diabetic patients, lifestyle changes and pharmacological therapy is required for type 2 diabetes in the young. ${ }^{76}$ Insulin therapy has been widely used for type 2 diabetic youth. Insulin therapy is particularly useful when it is still unclear whether a patient has type 1 or type 2 (especially atypical) diabetes. Metformin therapy has been increasingly used to treat type 2 diabetes in teenagers. Unfortunately, African American youth with either type 1 or type 2 diabetes are less well controlled than white diabetic youth. ${ }^{82-84}$ Standard hospital based or subspecialty clinic based protocols have had disappointing results in managing young African American diabetic patients. ${ }^{82}{ }^{84}$ However, the importance and efficacy of family support in improving diabetic control among African American youth has been shown. When a family member or caregiver is consistently involved in the management of the child's diabetes and actively supervises the child's care, HbAlc levels are significantly improved, compared with children whose caregivers only sporadically participate in their diabetes management. ${ }^{83}$

\section{ATYPICAL DIABETES}

A review of diabetes in the African American community would not be complete without a discussion of the "atypical" diabetes that has been described in this population. African Americans with type 2 diabetes have been found to have two

\section{Key references}

- Dagogo-Jack S. Ethnic disparities in type 2 diabetes: pathophysiology and implications for prevention and management. J Natl Med Asooc 2003;95:774-89.

- Banerii MA, Lebovitz HE. Insulin action in black Americans with NIDDM. Diabetes Care 1992;10:1295-302.

- Cook CB, Ziemer DC, El-Kebbi IM, et al. Diabetes in urban African-Americans. XVI. Overcoming clinical inertia improves glycemic control in patients with type 2 diabetes. Diabetes Care 1999;22:1494-500.

- McFarlane SI, Chaiken RI, Hirsh S, et al. Nearnormoglycemic remission in African-Americans with type 2 diabetes mellitus is associated with recovery of beta cell function. Diabet Med 2001;18:10-16.

- Winter WE, Nakamura M, House DV. Monogenic diabetes mellitus in youth. The MODY syndromes. Endocrinol Metab Clin North Am 1999;28:765-85.

distinctive atypical features. The first is that adult African American diabetics may present with classic signs and symptoms of DKA and thus look like type 1 diabetic patients. However, unlike type 1 diabetic patients: (1) these patients have no autoimmune markers of type 1 diabetes; (2) they are often obese; (3) there is evidence of insulin resistance; and (4) most importantly, after intensive therapy, spontaneous remission is the rule, with restoration of $\beta$ cell function within months and maintenance of normoglycaemia with oral agents or only dietary treatment. ${ }^{85-88}$ These patients have impaired insulin secretion when admitted with $\mathrm{DKA}^{87}$ but their subsequent clinical course is typical of type 2 diabetes. ${ }^{85-87}$ Recurrence of DKA is infrequent. Among those patients who remain insulin-requiring, recurrence of DKA is most often caused by non-compliance with insulin therapy. ${ }^{87} 8990$

The other unique feature of diabetes in African Americans is that spontaneous remission is also seen among patients who are not ketotic. When adult African Americans with newly diagnosed type 2 diabetes receive an average of three months of intensive, multidisciplinary therapy, $30 \%-40 \%$ of these patients will go into remission-that is, they will achieve normoglycaemia without pharmacological therapy. ${ }^{91}{ }^{92}$ Those who remit have a significantly greater return of $\beta$ cell function. However, there are no clinical characteristics that can differentiate those who will remit from those who will not. ${ }^{91}$ There is evidence that these atypical features are also present in African American children and adolescents with type 2 diabetes. ${ }^{93}$

It bears remembering that the African American diabetic patient who is initially controlled with insulin need not necessarily remain on insulin therapy, and the African American diabetic patient who is initially controlled with oral agents need not necessarily remain on pharmacological therapy. ${ }^{94}$

\section{METABOLIC SYNDROME}

Syndrome $X$ was promulgated by Reaven ${ }^{95}$ in an address to the American Diabetes Association. Reaven recognised the association of insulin resistance and hyperinsulinaemia with heart disease. He postulated a causal relation between hyperinsulinaemia and hypertension, dyslipidaemia, and coronary artery disease. This syndrome has been called by many names: syndrome $X$, metabolic syndrome $X$, insulin resistance syndrome, dysmetabolic syndrome, multiple metabolic syndrome, and deadly quartet. Currently, this clustering 
of risk factors is now defined as the metabolic syndrome. ${ }^{96}$ The criterion proposed for the diagnosis of the metabolic syndrome is the presence of three or more of the following abnormalities: (1) abdominal obesity: waist circumference $>102 \mathrm{~cm}$ in men and $>88 \mathrm{~cm}$ in women; (2) hypertriglyceridaemia: $\geqslant 1.69 \mathrm{mmol} / \mathrm{l}$; (3) low levels of high density lipoprotein (HDL) cholesterol: $<1.04 \mathrm{mmol} / \mathrm{l}$ in men and $<1.29 \mathrm{mmol} / \mathrm{l}$ in women; (4) hypertension: blood pressure $\geqslant 130 / 85 \mathrm{~mm} \mathrm{Hg}$; and (5) high fasting glucose: $\geqslant 6.1 \mathrm{mmol} / \mathrm{l}$.

While some investigators have questioned a specific insulin resistance syndrome among African Americans, ${ }^{97}$ others have found ample support for the existence of the metabolic syndrome in the African American community. ${ }^{98-100}$ The importance of the metabolic syndrome is that this particular clustering of specific abnormalities is especially predictive of both overt diabetes and accelerated cardiovascular risk, ${ }^{98} 101$ and cardiovascular disease is the leading cause of death in diabetic patients. ${ }^{102}$ This is particularly relevant to African Americans who have the highest mortality rate from coronary artery disease of any ethnic group in the USA. ${ }^{103}$ The age adjusted prevalence of the metabolic syndrome among US adults is $24 \% .{ }^{104}$ African American men have a lower prevalence compared with white men (16\% v 25\%), but African American women have a higher prevalence compared with white women $(26 \% v 23 \%)$. ${ }^{104}$

The metabolic syndrome can be effectively treated by lifestyle changes-that is, weight reduction and increased physical activity ${ }^{98}{ }^{101}$ - which are capable of improving all of the components of the syndrome. Although, lifestyle changes constitute the first line of treatment, they are often insufficient to fully reverse all the abnormalities of the metabolic syndrome. Pharmacological treatment may be necessary to achieve the desired goals of lipid levels, blood pressure, and glucose levels. Multiple drug therapy directed at these individual components is recommended. ${ }^{101}{ }^{105}$ Preliminary studies have found thiazolidinediones, metformin, angiotensin converting enzyme inhibitors, and angiotensin receptor blockers to be effective, to varying degrees, in improving insulin sensitivity, reducing cardiovascular risk, and inhibiting the progression to overt diabetes. ${ }^{105-109}$ However, there are no evidence base data to support the use of any single agent to treat the metabolic syndrome.

\section{CONCLUSION}

African American adults, adolescents, and children have a high risk for, and a high prevalence of insulin resistance and overt type 2 diabetes mellitus. African American diabetic patients receive lower quality health care, are less well controlled, and consequently have a higher rate of complications than white diabetic patients. Some African American diabetic patients have an atypical presentation that simulates type 1 diabetes, but their subsequent clinical course is typical of type 2 diabetes. There is a paucity of evidence based data on pharmacological treatment for African American diabetic patients. However, primary care of the African American diabetic patient can be greatly assisted by structured disease management protocols. The use of case management nurses, diabetes educators, and other health care professionals is particularly effective in improving glycaemic control in the African American diabetic community.

\section{QUESTIONS (ANSWERS AT END OF REFERENCES)}

1. An African American patient who presents with diabetic ketoacidosis will require lifelong insulin treatment.

2. The possible reasons for the prevalence of poor glycaemic control among African American diabetic patients include the following, except:
(A) Racial disparities in health care result in lower quality care for African Americans.

(B) A low socioeconomic status for most African Americans hinders access to health care.

(C) African American diabetic patients receive less intensive pharmacological treatment than white diabetic patients

(D) A reduced efficacy of oral antidiabetic drugs has been reported in African American subjects.

3. Insulin is less likely to be effective in African American diabetic patients than white diabetic patients.

4. The metabolic syndrome is particularly important in the African American community because:

(A) It is associated with an accelerated cardiovascular risk.

(B) It is associated with a high rate of lower extremity amputation.

(C) It can be effectively treated by single drug therapy.

(D) There is no association with abdominal obesity.

5. All of the following statements are true, except:

(A) Metformin is generally recommended as initial pharmacological treatment for obese diabetic patients.

(B) There are scarce evidence based data on specific pharmacological treatment for African American diabetic patients.

(C) Lifestyle changes (diet and exercise) will not improve glycaemic control in African American diabetic patients.

(D) Intensive treatment of a newly diagnosed African American diabetic patient may lead to remission of the diabetes.

6. Which of the following statements is true:

(A) The thrifty gene theory refers to increased expenditure of calories in the face of increased calorific consumption.

(B) There is a higher prevalence of autoimmune markers in African American diabetic patients than white diabetic patients.

(C) African American children have a lower prevalence of insulin resistance than white children.

(D) African American women have a higher prevalence of the metabolic syndrome than white women.

Funding: none.

Conflicts of interest: none declared.

\section{REFERENCES}

1 Harris MI, Flegal KM, Cowie CC, et al. Prevalence of diabetes, impaired fasting glucose, and impaired glucose tolerance in US adults. Diabetes Care 1998;21:518-24.

2 Kenny SJ, Aubert RE, Geiss LS. Prevalence and incidence of non-insulindependent diabetes. In: National Diabetes Data Group, eds. Diabetes in America. 2nd ed. Bethesda, MD: NIH, 1995:47-68.

3 American Diabetes Association. Standards of medical care in diabetes (position statement). Diabetes Care 2004;27(suppl 1):S15-35.

4 American Diabetes Association. Diabetes 2001 vital statistics. Alexandria, VA: American Diabetes Association, 2001:87-109.

5 Radhakrishnamurthy B, Srinivasan SR, Webber LS, et al. Relationship of carbohydrate intolerance to serum lipoprotein profiles in childhood: the Bogalusa heart study. Metabolism 1985;34:850-60.

6 Paris RM, Bedno SA, Krauss MR, et al. Weighing in on type 2 diabetes in the military. Diabetes Care 2001;24:1894-98.

7 Gu K, Cowie CC, Harris MI. Mortality in adults with and without diabetes in a national cohort of the US population, 1971-1993. Diabetes Care 1998;21:1138-45.

8 Chin MH, Zhang JX, Merrell K. Diabetes in the African-American medicare population: quality of care, an resource utilization. Diabetes Care 1998;21:1090-5. 
9 Arfken CL, Reno PL, Santiago JV, et al. Development of proliferative diabetic retinopathy in African-Americans and whites with type 1 diabetes. Diabetes Care 1998;21:792-5.

10 Harris MI. Racial and ethnic differences in health care access and health outcomes for adults with type 2 diabetes. Diabetes Care 2001;24:454-9.

11 American Diabetes Association. Diabetes 2001 vital statistics. Alexandria, VA: American Diabetes Association, 2001:90-2.

12 Summerson JH, Bell RA, Konen JC, et al. Differential impact of cardiovascular disease (CVD) risk factor clustering on CVD and renal disease among African-Americans and white patients with type 2 diabetes mellitus. Ethn Dis 2002; 12:530-4

13 Young BA, Maynard C, Reiber G, et al. Effects of ethnicity and nephropathy on lower extremity amputation risk among diabetic veterans. Diabetes Care 2003;26:495-501

14 Young BA, Maynard C, Boyko EJ. Racial differences in diabetic nephropathy, cardiovascular disease, and mortality in a national population of veterans. Diabetes Care 2003:26:2392-9.

15 Tull ES, Roseman JM. Diabetes in African Americans. In: National Diabetes Data Group, eds. Diabetes in America. 2nd ed. Bethesda, MD: NIH, 1995:413-629.

16 Dagogo-Jack S. Ethnic disparities in type 2 diabetes: pathophysiology and implications for prevention and management. J Natl Med Assoc 2003;95:774-89.

17 Gaskin R. Diet, diabetes, hypertension and blacks. Ethn Dis 1999;9:272-7.

18 Neel JV. Diabetes mellitus-a thrifty genotype rendered detrimental by progress? Am J Hum Genet 1962;14:353-62.

19 Ong KK, Dunger DB. Thrifty genotypes and phenotypes in the pathogenesis of type 2 diabetes mellitus. J Pediatr Endocrinol Metab 2000; 13/suppl 6): 1419-24.

20 Baschetti R. Diabetes epidemic in newly westernized populations: is it due to thrifty genes or to genetically unknown foods? J R Soc Med 1998;91:622-5.

21 Osei K. Metabolic consequences of the West African diaspora: lessons from the thrifty gene. J Lab Clin Med 1999;133:98-111.

22 El-Kebbi IM, Cook CB, Ziemer DC, et al. Association of younger age with poor glycemic control and obesity in urban African Americans with type 2 diabetes. Arch Intern Med 2003;163:69-75.

23 Wolfe WA. Obesity and the African American woman: a cultural tolerance of fatness or other neglected factors? Ethn Dis 200, 10:446-53.

24 Palaniappan LP, Carnethon MR, Fortmann SP. Heterogeneity in the relationship between ethnicity, BMI, and fasting insulin. Diabetes Care 2002;25:1351-7.

25 Carnethon MR, Palaniappan LP, Burcafiel CM, et al. Serum insulin, obesity, and the incidence of type 2 diabetes in black and white adults. The atherosclerosis risk in communities study: 1987-1998. Diabetes Care 2002;25: 1358-64

26 Crosstow N, Falkner B. Race/ethnic issues in obesity and obesity-related comorbidities. J Clin Endocrinol Metab 2004;89:2590-4.

27 American Diabetes Association. Screening for type 2 diabetes (position statement). Diabetes Care 2004;27(suppl 1):S11-14.

28 American Diabetes Association. Diabetes 2001 vital statistics. Alexandria, VA: American Diabetes Association, 2001:29-42.

29 American Diabetes Association. Physical activity/exercise and diabetes (position statement). Diabetes Care 2004;27(suppl 1):S58-62.

30 Kimm SYS, Glynn NW, Kriska AM, et al. Decline in physical activity in black girls and white girls during adolescence. N Engl J Med 2002;347:709-15.

31 Pearte CA, Gary TL, Brancati FL. Correlates of physical activity levels in a sample of urban African Americans with type 2 diabetes. Ethn Dis 2004; 14:198-205.

32 Goran MI, Bergman RN, Cruz ML, et al. Insulin resistance and associated compensatory responses in African-American and Hispanic children. Diabetes Care 2002;25:2184-90.

33 Svec F, Nastasi K, Hilton C, et al. Black-white contrasts in insulin levels during pubertal development. Diabetes 1992:41:313-17.

34 Haffner SM, Howard G, Mayer C, et al. Insulin sensitivity and acute insulin response in African Americans, non-Hispanic whites, and Hispanics with NIDDM: the insulin resistance atherosclerosis study. Diabetes 1997:46:63-9.

35 Banerii MA, Lebovitz HE. Insulin action in black Americans with NIDDM. Diabetes Care 1992;10:1295-302.

36 Haffner SM, D'Agostino R, Saad MF, et al. Increased insulin resistance and insulin secretion in nondiabetic African-Americans and Hispanics compared with non-Hispanic whites. The insulin resistance atherosclerosis study. Diabetes 1996;45:742-8.

37 Harris MI, Cowie CC, Gu K, et al. Higher fasting insulin but lower fasting Cpeptide levels in African Americans in the US population. Diabetes Metab Res Rev 2002;18:149-55.

38 The Diabetes Control and Complications Trial Research Group. The effect of intensive treatment of diabetes on the development and progression of longterm complications in insulin-dependent diabetes mellitus. N Engl J Med 1993:329:977-86

39 UK Prospective Diabetes Study Group. Intensive blood-glucose control with sulphonylureas or insulin compared with conventional treatment and risk of complications in patients with type 2 diabetes (UKPDS 33). Lancet 1998;352:837-53

40 Saadine JB, Engelgau MM, Beckles GL, et al. A diabetes report card for the United States: quality of care in the 1990s. Ann Intern Med 2002; 136:565-74

41 Koro CE, Bowlen SJ, Bourgeois N, et al. Glycemic control from 1988 to 2000 among US adults diagnosed with type 2 diabetes. A preliminary report. Diabetes Care 2004;27:17-20.
42 de Rekeniere N, Rooks RN, Simonson EM, et al. Racial differences in glycemic control in a well-functioning older diabetic population. Findings from the health, aging and body composition study. Diabetes Care 2003;26: 1986-92

43 Bonds DE, Zacaro DJ, Karter AJ, et al. Ethnic and racial differences in diabetes care. Diabetes Care 2003;26:1040-6

44 Heisler M, Smith DM, Hayward RA, et al. Racial disparities in diabetes care processes, outcomes, and treatment intensity. Med Care 2003:41:1221-32.

45 Harris MI, Eastman RC, Cowie CC, et al. Racial and ethnic differences in glycemic control of adults with type 2 diabetes. Diabetes Care 1999;22:403-8.

46 Schectman JM, Nadkarni MM, Voss JD. The association between diabetes metabolic control and drug adherence in an indigent population. Diabetes Care 2002;25:1015-21.

47 El-Kebbi IM, Ziemer DC, Musey VC, et al. Diabetes in urban African Americans. IX. Provider adherence to management protocols. Diabetes Care 1997; 20:698-703.

48 Smedley BD, Stith AY, Nelson AR, Institute of Medicine (US) Committee on Understanding and Eliminating Racial and Ethnic Disparities in Health Care. Unequal treatment Confronting racial and ethnic disparities in healthcare. Washington, DC: National Academy Press, 2002.

49 Franz MJ, Warshaw H, Daly AE, et al. Evolution of diabetes medical nutrition therapy. Postgrad Med J 2003;79:30-5.

50 Diabetes Prevention Program Research Group. Reduction in the incidence of type 2 diabetes with lifestyle intervention or metformin. N Engl J Med 2002;346:393-403

51 Diabetes Prevention Program Research Group. The diabetes prevention program. Diabetes Care 2000;23:1619-29.

52 Keyserling TC, Samuel-Hodge CD, Ammerman AS, et al. Randomized trial of an intervention to improve self-care behaviors of African-American women with type 2 diabetes. Impact on physical activity. Diabetes Care 2002:25:1576-83.

53 Ziemer DC, Berkowitz KJ, Panayioto RM, et al. A simple meal plan emphasizing healthy food choices ia as effective as an exchange-based meal plan for urban African Americans with type 2 diabetes. Diabetes Care 2003:26:1719-24.

54 Burroughs VJ, Maxey RW, Levy RA. Racial and ethnic differences in response to medicines: towards individualized pharmaceutical treatment. J Natl Med Assoc 2002;94:1-26.

55 Physicians' Desk Reference. 58th ed. Montvale, NJ: Thomson PDR, 2004

56 DeFronzo RA. Pharmacologic therapy for type 2 diabetes mellitus. Ann Intern Med 1999;131:281-303.

57 Inzucchi S. Oral antihyperglycemic therapy for type 2 diabetes mellitus: scientific review. JAMA 2002;287:360-72.

58 Nathan DM. Clinical practice. Initial management of glycemia in type 2 diabetes mellitus. N Engl J Med 2002;347:1342-9.

59 Misbin RI. The phantom of lactic acidosis due to metformin in patients with diabetes. Diabetes Care 2004;27:1791-3.

60 Mudaliar S, Henry RR. The oral antidiabetic agents. In: Porte D, Sherwin RS Baron A, eds. Ellenberg and Rifkin's diabetes mellitus. New York: McGrawHill, 2003:531-64.

61 Osei K, Rhinesmith S, Gaillard T, et al. Metabolic effects of chronic glipizide gastrointestinal therapeutic system on serum glucose, insulin secretion, insulin sensitivity, and hepatic insulin extraction in glucose-tolerant, first-degree relatives of African American patients with type 2 diabetes: new insights on mechanisms of action. Metabolism 2003;52:565-72.

62 Schuster D, Gaillard T, Rhinesmith S, et al. The impact of an insulin sensitizer, troglitazone, on glucose metabolism in African Americans at risk for type 2 diabetes mellitus: a placebo-controlled, 24-month randomized study. Metabolism 2003;52:1211-17.

63 Maggs D, Shen L, Strobel S, et al. Effect of pramlintide on Alc and body weight in insulin-treated African Americans and Hispanics with type 2 diabetes: a pooled post hoc analysis. Metabolism 2003:52:1638-42.

64 Osei K, rhinesmith S, Gaillard T, et al. Beneficial metabolic effects of chronic glipizide in obese African Americans with impaired glucose tolerance: implications for primary prevention of type 2 diabetes. Metabolism 2004;53:414-22.

65 Agrawal L, Emanuele NV, Abraira C, et al. Ethnic differences in the glycemic response to exogenous ihsulin treatment in the veterans affairs cooperative study in type 2 diabetes mellitus (VA CSDM). Diabetes Care 1998:21:510-15.

66 Rosenstock J, Schwartz SL, Clark CM, et al. Basal insulin therapy in type 2 diabetes. Diabetes Care 2001;24:631-6.

67 Yki-Jarvinen H. Combination therapies with insulin in type 2 diabetes. Diabetes Care 2001;24:758-67.

68 Riddle M, Rosenstock J, Gerich J. The treat-to-target trial. Diabetes Care 2003:26:3080-6

69 Nathan DM. Insulin treatment of type 2 diabetes mellitus. In: Porte D, Sherwin RS, Baron A, eds. Ellenberg and Rifkin's diabetes mellitus. New York: McGraw-Hill, 2003:515-22.

70 Fanelli CG, Pampanelli S, Percellati F, et al. Administration of neutral protamine Hagedorn insulin at bedtime versus with dinner in type 1 diabetes mellitus to avoid nocturnal hypoglycemia and improve control. A randomized, controlled trial. Ann Intern Med 2002;136:504-14

71 Cook CB, Ziemer DC, El-Kebbi IM, et al. Diabetes in urban AfricanAmericans. XVI. Overcoming clinical inertia improves glycemic control in patients with type 2 diabetes. Diabetes Care 1999;22:1494-500.

72 Davidson MB. Effect of nurse-directed diabetes care in a minority population. Diabetes Care 2003;26:2281-7.

73 The California Medi-Cal Type 2 Diabetes Study Group. Closing the gap: effect of diabetes case management on glycemic control among low-income 
ethnic minority populations, The California Medi-Cal type 2 diabetes study. Diabetes Care 2004;27:95-103.

74 Thaler LM, Ziemer DC, Gallina DL, et al. Diabetes in urban AfricanAmericans. XVII. Availability of rapid $\mathrm{HbAlc}$ measurements enhances clinical decision-making. Diabetes Care 1999;22:1415-21.

75 Karter AJ, Ferrara A, Liu JY, et al. Ethnic disparities in diabetic complications in an insured population. JAMA 2002;287:2519-27.

76 Bloomgarden ZT. Type 2 diabetes in the young: the evolving epidemic. Diabetes Care 2004;27:998-1010.

77 Winter WE, Nakamura M, House DV. Monogenic diabetes mellitus in youth. The MODY syndromes. Endocrinol Metab Clin North Am 1999;28:765-85.

78 Winter WE. Molecular and biochemical analysis of the MODY syndromes. Pediatr Diabetes 2000;1:88-117.

79 Shin DQ, Stoffel M. Molecular etiologies of MODY and other early-onset forms of diabetes. Curr Diab Rep 2002;2:125-34.

80 Porter JR, Barrett TG. Acquired non-type 1 diabetes in childhood: subtypes, diagnosis, and management. Arch Dis Child 2004;89:1138-44.

81 Apedo MT, Sowers JR, Banerii MA. Cardiovascular diseases in adolescents with type 2 diabetes mellitus. J Pediatr Endocrinol Metab 2002;15/suppl 1):519-23.

82 Chalew SA, Gomez R, Butler A, et al. Predictors of glycemic control in children with type 1 diabetes: the importance of race. $J$ Diabetes Complications 2000;14:71-7.

83 Bradshaw B. The role of family in managing therapy in minority children with type 2 diabetes mellitus. J Pediatr Endocrinol Metab 2002;15(suppl 1):547-51.

84 El-Kebbi IM, Cook CB, Ziemer DC, et al. Association of younger age with poor glycemic control and obesity in urban African Americans with type 2 diabetes. Arch Intern Med 2003;163:69-75.

85 Banerii MA. Diabetes in African Americans: unique pathophysiologic features. Curr Diab Rep 2004;4:219-23.

86 Umpierrez GE, Kelly JP, Navarrete JE, et al. Hyperglycemic crises in urban blacks. Arch Intern Med 1997;157:669-75.

87 Umpierrez GE, Casals MM, Gebhart SP, et al. Diabetic ketoacidosis in obese African-Americans. Diabetes 1995;44:790-5.

88 Banerii MA, Chaiken RL, Huey H, et al. GAD antibody negative NIDDM in adult black subjects with diabetic ketoacidosis and increased frequency of human leukocyte antigen DR3 and DR4. Flatbush diabetes. Diabetes 1994;43:741-5.

89 Maldonaldo MR, Otiniano ME, Lee R, et al. Characteristics of ketosis-prone diabetes in a multiethnic indigent community. Ethn Dis 2004:14:243-9.

90 Musey VC, Lee JK, Crawford R, et al. Diabetes in urban African-Americans. I. Cessation of insulin therapy is the major precipitating cause of diabetic ketoacidosis. Diabetes Care 1995; 18:483-9.

91 McFarlane Sl, Chaiken Rl, Hirsch S, et al. Near-normoglycaemic remission in African-Americans with type 2 diabetes mellitus is associated with recovery of beta cell function. Diabet Med 2001;18:10-16.

92 Banerii MA, Chaiken RL, Lebovitz HE. Long-term normoglycemic remission in black newly diagnosed NIDDM subjects. Diabetes 1996:45:337-41.
93 Banerii MA. Impaired beta-cell and alpha-cell function in African-American children with type 2 diabetes mellitus - "Flatbush diabetes". J Pediatr Endocrino Metab 2002;15(suppl 1):493-501.

94 Cook CB, Lyles RH, El-Kebbi I, et al. The potentially poor response to outpatient diabetes care in urban African-Americans. Diabetes Care 2001;24:209-15

95 Reaven GM. Banting Lecture 1988. Role of insulin resistance in human disease. Diabetes 1988;37:1595-607.

96 Expert Panel on Detection, Evaluation, and Treatment of High Blood Cholesterol in Adults. Executive summary of the Third Report of the National Cholesterol Education Program (NCEP) Expert Panel on Detection, Evaluation, and Treatment of High Blood Cholesterol in Adults (Adult Treatment Panel IIII. JAMA 2001;285:2486-97.

97 Chaiken RL, Banerii MA, Huey H, et al. Do blacks with NIDDM have an insulin-resistance syndrome? Diabetes 1993;42:444-9.

98 Hall WD, Clark LT, Wenger NK, et al. The metabolic syndrome in African Americans: a review. Ethn Dis 2003;13:414-28.

99 Falkner B. Insulin resistance in African Americans. Kidney Int Suppl 2003:63:S27-30.

100 Schmidt MI, Duncan BB, Watson RL, et al. A metabolic syndrome in whites and African-Americans. The atherosclerosis risk in communities baseline study. Diabetes Care 1996;19:414-18.

101 American College of Endocrinology Task Force on the Insulin Resistance Syndrome. Position statement on the insulin resistance syndrome. Endocr Pract 2003;9:236-52.

102 Beckman JA, Creager MA, Libby P. Diabetes and atherosclerosis. Epidemiology, pathophysiology, and management. JAMA 2002:287:2570-81.

103 Clark LT, Ferdinand KC, Flack JM, et al. Coronary heart disease in African Americans. Heart Dis 2001;3:97-108.

104 Ford ES, Giles WH, Dietz WH. Prevalence of the metabolic syndrome among US adults. JAMA 2002;287:356-9.

105 Rosenson RB, Reasner CA. Therapeutic approaches in the prevention of cardiovascular disease in metabolic syndrome and in patients with type 2 diabetes. Curr Opin Cardiol 2004;19:480-7.

106 Caballero AE. Endothelial dysfunction, inflammation, and insulin resistance: a focus on subjects at risk for type 2 diabetes. Curr Diab Rep 2004;4:237-46.

107 Scheen AJ. Management of the metabolic syndrome. Minerva Endocrinol 2004;29:31-45.

108 Derosa G, Cicero AF, Gaddi A, et al. Metabolic effects of pioglitazone and rosiglitazone in patients with diabetes and metabolic syndrome treated with glimepiride: a twelve-month, multicenter, double-blind, randomized, controlled, parallel-group trial. Clin Ther 2004;26:744-54.

109 Wagh A, Stone NJ. Treatment of metabolic syndrome. Expert Rev Cardiovasc Ther 2004;2:213-28.

\section{ANSWERS}

1. False; 2. (C); 3. false; 4. (A); 5. (C); 6. (D). 